\title{
Analisis Wacana Kritis Terhadap Film Munafik 2
}

\author{
Megandini Al Fiqri ${ }^{1 *}$, Sitty Sumijati ${ }^{1}$, Asep Shodiqin ${ }^{2}$ \\ ${ }^{1,2}$ Jurusan Komunikasi dan Penyiaran Islam, Fakultas Dakwah dan Komunikasi, UIN Sunan \\ Gunung Djati, Bandung \\ *Email : megandinialfiqri@gmail.com
}

\begin{abstract}
ABSTRAK
Penelitian ini bertujuan untuk mengetahui bagaiamana analisis teks, Kognisi Sosial, dan Konteks Sosial yang ada dalam Film Munafik 2. Penelitian ini menggunakan pendekatan kualitatif dengan metode Analisis Wacana Kritis Teun A Van Djik. Sasaran penelitian ini adalah Film Munafik 2. Adapun teknik pengumpulan data dilakukan dengan menonton film, mengklasifikasikan wacana dan menganalisis data-data yang ada. Setelah dilakukan analisis terhadap Film Munafik 2. Hasil penelitian ini menunjukan bahwa Film Munafik 2 ditinjau dari analisis teks secara umum film ini mengangkat tema kemunafikan yang disampaikan menggunakan bahasa melayu dengan majas yang beragam. Sedangkan kognisi sosial film ini berisi informasi Islam. Diantaranya informasi akidah, informasi syariat dan informasi akhlak Islam. Adapun konteks Film ini yakni adanya alur cerita yang disajikan secara plot twist bahkan Plot bole serta dialog yang disampaikan cenderung terlalu eksplisit dan kontras.
\end{abstract}

Kata Kunci : Analisis; Film; Munafik 2.

\section{ABSTRACT}

The purpose of this study is determine how the analysis of texts, social cognition, and social context in Film Munafik 2. This study used a qualitative approach with the method of Critical Discourse Analysis of Teun A Van Djik. The target of this research is Film Munafik. 2. The data collection technique is done by watching the movie, classifying discourses and analyzing existing data. After analyzing film Munafik 2. The results of this study indicate that film Munafik. 2 in terms of text analysis this film generally raises the theme of bypocrisy delivered using Malay language with a variety of majas. While the social cognition of this film contains Islamic information. Among them is aqidah, law, and Islamic morals information. The context of this film is the existence of a plot that is presented in a plot twist and even plot holes and the dialogue that is delivered tends too explicit and contrasting.

Keywords : Analysis; Film; Munafik 2. 


\section{PENDAHULUAN}

Dakwah masa kini dilakukan secara dinamis menggunakan berbagai media dan metode yang beragam. Dakwah sebagai cara yang mudah untuk mengubah suatu keadaan masyarakat menjadi lebih baik. Dalam pengertian Syari'ah, meskipun zaman dan perkembangan teknologi berkembang sangat pesat, dakwah harus selalu ada. (Muhaemin, 2017: 341-342)

Saat ini dakwah tidak disampaikan diatas mimbar saja. Kecanggihan teknologi dan perkembangan masyarakat yang homogen dan heterogen membuat segala hal yang bisa dijadikan alat atau sarana dakwah maka itu disebut media. Berdasarkan jenisnya, ada tiga media yang digunakan sebagai perantara dakwah. Yakni media audio, visual, dan audiovisual. Diantara semuanya media audio visual merupakan media yang paling menarik. Selain bisa melihat tayangannya penonton pun bisa mendengar apa dibicarakan pada media tersebut. Dari beberapa produk Audio Visual yang paling efektif aadalah Film. (Nursyamsi. Y.F., 2018: 92)

Film sebagai media dakwah memilki nilai plus diantara media-media lainnya. Film sebagai media dakwah yang efektif, karena nasihat-nasihatnya diberikan kepada penonton secara halus dan menyentuh lubuk hati tanpa merasa didakwahi. Hal ini sesuai dengan ajaran Allah SWT bahwa untuk menyampaikan dakwah, lebih baik dilakukan menggunakan 'Perkataan yang halus', yaitu pesan yang disampaikan dengan benar, menyentuh, dan membekas dalam hati (Kusnawan 2004: 95)

Film menjadi salah satu alat transmisi informasi media massa melalui komunikasi massa. Ditinjau dari segi fungsinya, film memiliki kesatuan fungsi dengan media massa

Sebagai bentuk komunikasi massa, film dikelola menjadi suatu komoditi. didalamnya memang kompleks, dari produser, pemain, hingga seperangkat kesenian lain yang sangat mendukung seperti musik, seni rupa, teater, dan seni suara. Semua unsur tersebut terkumpul menjadi komunikator dan bertindak sebagai agen transformasi budaya. (Baskin, 2003: 7)

.Menurut Alexis S Tan Film sebagai komunikasi massa memiliki fungsi pertama, Informasi (To inform), yakni menginformasikan kepada khalayak perihal peristiwa baik yang bersifat lokal, regional, nasional, maupun internasional. Kedua, Mengedukasi (To educate), yakni mendidik atau memberikan pengetahuan dan keterampilan yang bermanfaat bagi masyarakat luas. Ketiga, Mengajak (To persue), yakni mempersuasi khalayak dalam pengambilan keputusan, pengadopsian nilai, perilaku, dan aturan yang sesuai dan diterima masyarakat. Dan terakhir, menghibur (To entertain), yakni menghibur khalayak khususnya penonton, memberikan kesenangan dan kepuasan kepada khalayak. (Nurdin, 2009: 65) 
Film memberikan pengaruh yang kuat pada penontonnya. Pada saat menonton film, manusia mengalami keadaan yang disebut dalam Psikologi sebagai gejala psikologis. (Kusnawan 2004: 93)

Secara umum orang yang sedang menonton film kerap menyamakan kondisinya dengan salah seorang pemeran yang ada dalam film tersebut. Penonton dapat merasakan apa yang dialami oleh salah satu tokoh film tersebut, bahkan, mereka juga merasa seakan-akan mengalami sendiri adegan-adegan dalam film. (Enjang, 2004: 93)

Film juga mempunyai banyak elemen-elemen yang tersusun menjadi susunan yang menarik. elemen-elemen yang berhubungan dengan alat kelamin, perbuatan yang melanggar hukum, percintaan, kekerasan, rasialisme dan sejarah adalah elemen-elemen cerita yang bisa menyentuh hati penonton, yang bisa membuat penonton takjub, yang bisa membuat penonton tertawa terbahakbahak, menangis terisak-isak, bisa membuat penonton dongkol, marah, terharu, iba, bangga, gembira, tegang dan lain-lain. Maka diambillah riwayat-riwayat dari buku-buku, kisah-kisah dari sejarah, cerita nyata kehidupan sehari-hari, atau fiksi untuk kemudian diproduksi menjadi sebuah film. (Effendy, 2003: 212)

Oleh karena itu, film adalah sarana komunikasi yang ampuh, bukan hanya untuk hiburan, tetapi juga untuk informasi dan edukasi. (Effendi: 2003).

Produksi film di Indonesia saat ini mengalami kemajuan yang sangat pesat, dan disukai oleh semua kalangan, mulai dari anak-anak, remaja, dewasa, sampai orang tua. Film yang berada di pasaran tersebut memilki beragam konten yang memiliki nilai positif maupun negatif. Produk Film positif terutama film yang berisi konten Islami dan memiliki nilai dakwah diminati para pecinta film Islami. (Soleh, 2019: 17)

Film bermuatan ajaran Islam tidak harus selalu bergenre religi saja. film yang mengangkat nilai-nilai universal dan humanistik pun bisa dimanifestasikan dalam proses pembuatan film dakwah. Untuk menyampaikan misi Islam, bisa saja dikemas dalam jenis Film genre apapun; asalkan tujuannya jelas, pesan-pesan dakwahpun dapat tersampaikan dengan baik.

Film Munafik 2 merupakan salah satu contoh media dakwah yang dikemas dengan menarik dalam genre horror religi. Film garapan Syamsul Yusof ini berhasil mengambil perhatian masyarakat sehingga menjadi film terlaris sepanjang masa di Malaysia. Film ini juga mendapatkan respon positif di Indonesia. Film ini terinspirasi dari kisah para Nabi dalam memperjuangkan agama Islam. Kemunculannya ditengah banyaknya Film-film lainnya yang diproduksi menarik untuk dianalisis karena film ini mengusung tema dakwah Islam. Selain itu alur dan dialog dalam film ini mampu membuat penonton menangis lantaran adegan-adegan yang ada dalam film ini ciamik dan menyentuh. 
Hal menarik lainnya dalam film ini yaitu karena menggunakan nama 'munafik' sebagai judul yang notabenenya digunakan masyarakat Islam. Film ini juga sarat akan muatan pesan dakwah. Tak sedikit masyarakat yang mengatakan bahwa film ini memotivasi penonton untuk lebih mendekatkan diri pada Tuhan. Film ini tidak hanya layak menjadi tontonan, akan tetapi dalam film ini pun mengandung tuntunan yang dapat dimanifestasikan dalam bentuk perbuatan.

Dalam penelitian analisis wacana kritis (AWK) Teun A Van Djik; Penelitian ini difokuskan pada 3 elemen; yaitu: analisis teks, kognisi sosial, dan konteks sosial yang ada dalam film Munafik 2. Sedangkan teknik pengumpulan data diperoleh dari hasil observasi dan studi dekumentasi. Adapun jenis data yang digunakan yaitu data kualitatif, penulis menonton film Munafik 2 di bioskop dan mengunduh video film Munafik 2 di youtube yang menampilkan adegan-adegan pemain film Munafik 2 sebagai bahan analisis.

\section{LANDASAN TEORITIS}

Analisis wacana kritis Film Munafik 2 memiliki dua landasan penting yakni landasan teoritis dan konseptual. Pada penelitian ini ada beberapa teori dan konsep yang dijadikan kajian penelitian diantaranya teori fungsi film, jenis-jenis film, unsur-unsur dakwah, dan media dakwah. Adapun konsep yang digunakan diantaranya konsep dakwah dan Analisis wacana kritis Teun A Van Djik.

Secara bahasa kata dakwah memiliki arti: Memanggil; Menyeru; Menegaskan atau membela sesuatu; perkataan atau perbuatan untuk menarik manusia kepada sesuatu; dan memohon dan meminta, atau do'a. (Abdul Aziz, 1997: 26).

Secara Istilah kata Dakwah memiliki makna yang berdekatan dengan ta'lim, tad乏hir, dan tashwir. Meskipun setiap konsep tersebut memiliki maksud serta obyek yang berbeda, namun substansinya sama yaitu menyebarkan ajaran Islam kepada manusia, baik yang berkaitan dengan dirasah Islamiyah ataupun sejarahnya.

Ta'lim dalam bahasa Indonesia memiliki arti mengajar, maksudnya memberi pelajaran kepada orang lain, aktivitas ini bersifat promotif yaitu menambah pengetahuannya, sedangkan sasarannya adalah orang yang masih kurang pengetahuannya. Tadz̧bir dalam bahasa Indonesia memilki arti mengingatkan maksudnya memberi nasihat supaya selalu mengingat kewajibannya sebagai orang Islam. Karena aktivitas ini bertujuan untuk membetulkan yang salah, atau membetulkan tingkah laku yang tidak baik disebabkan pengaruh lingkungan keluarga, sosial budaya yang kurang baik. sedangkan Tashwir dalam bahasa Indonesia memiliki arti menggambarkan sesuatu pada alam pikiran seseorang, tujuannya meningkatkan pemahaman akan sesuatu melalui penggambaran atau penjelasan. aktivitasini bersifat persuasif, yaitu menanamkan ajaran agama kepada manusia, sehingga mereka terpengaruh dan mengikutinya. (Wahidin Saputra, 2012: 4) 
Elemen-elemen yang harus ada dalam kegiatan dakwah yakni, Da’i, mad'u, maudu', wasilah, dan pesan dakwah. Pembahasan lanjutannya difokuskan pada Wasilah (Media dakwah).

Media dakwah merupakan elemen penting bagi proses kelangsungan dakwah. Media dakwah adalah alat perantara penyampai pesan atau saluran pesan yang menghubungkan da'i dan mad'u. Media dakwah berdasarkan jenisnya terdiri dari tiga jenis; pertama, media tradisional, misalnya: gema, bedug, rebana dan lain lain; kedua, media modern, yakni: mencakup media audio, visual atau audiovisual seperti radio, buku, dan film. serta ketiga, perpaduan media tradisional dan modern. Misalnya, ceramah yang ditayangkan di televisi. (Enjang AS \& Aliyudin, 2009: 95)

Pada dasarnya film adalah bentuk media informasi kepada penonton. Film memiliki kebebasan dalam menyampaikan informasi atau pesan-pesan dari sebuah tayangan kepada penontonnya. Kebebasan dalam hal ini adalah film bisa menyampaikan pesan dengan lugas dan jujur. Pada bagian lainnya film juga sering disertai dengan kecenderungan tertentu, misalnya ingin menjelaskan suatu tema pokok. Dengan tujuan ingin menyampaikan informasi, umumnya film digolongkan menjadi dua elemen penting yaitu film fiksi dan non fiksi. Gambaran cerita film menyajikan kepada penonton sebuah cerita dan mengandung elemen elemen yang menyentuh rasa manusia. Film yang bersifat audiovisual, yang dapat disajikan kepada penonton dalam bentuk gambar yang dapat dilihat dengan suara, yang dapat didengar dan merupakan suatu sajian yang sudah matang dan siap disantap. (Marsefio Luhukay, 2008:124-134)

Model penelitian teori analisis Wacana Kritis Teun A Van Djik merupakan jenis analisis yang paling banyak digunakan dalam penelitian. Model ini sering disebut sebagai "kognisi sosial", dalam hal ini penelitian tidak hanya terfokus pada teks akan tetapi pengamatan juga difokuskan pada bagaimana suatu teks dibuat. Proses pembuatan film dan pendekatan ini melibatkan suatu proses yang disebut kognisi sosial. (Darma, 2014: 124)

Analisis Van Djik dijelaskan memilki tiga elemen, yaitu teks, kognisi sosial, dan konteks sosial. Van Djik menggabungkan ketiga bagian wacana tersebut ke dalam satu kesatuan analisis. Pada analisis teks, yang diteliti adalah bagaimana struktur tulisan dan strategi wacana dipakai untuk menegaskan suatu cerita tertentu. Kognisi sosial menjelaskan proses induksi pesan berita yang melibatkan kognisi individu dari seseorang. Sedangkan aspek ketiga yaitu konteks sosial yakni menjelaskan bangunan wacana yang berkembang dalam masyarakat akan suatu masalah (Darma, 2014: 126). 
Megandini A Fiqri, Sitty Sumijati, Asep Shodiqin

\section{HASIL PENELITIAN DAN PEMBAHASAN}

Film Munafik 2 (2018) adalah film horor Malaysia dan merupakan sekuel kedua dari Film Munafik yang disutradarai oleh Syamsul Yusof. Film ini ditayangkan pada tahun 2016. Durasi film ini 121 menit. Diperankan olehAktor Malaysia seperti Syamsul Yusof, Maya Karin, Fizz Fairuz, Nasir Bilal Khan, Mawi, Fauzi Nawawi, Roslan Salleh, Ku Faridah, Nur Zara Sofia, dan Aktris Indonesia Weni Panca.

Film ini ditayangkan pada 30 Agustus 2018 di Malaysia dan 26 September 2018 di Indonesia. Film ini diproduksi oleh Skop production dengan estimasi biaya RM. 2.8 Milyar.

Cerita ini dibuat terinspirasi dari kisah para nabi. Film ini menjelaskan bagaimana rintangan yang dihadapi para nabi dan sahabatnya dalam menyampaikan ajaran Islam, memperjuangkan dan menyebarkan agama Islam. Ide utama dalam menulis cerita film ini juga dari Al Quran dan al Hadits. Bahkan salah satu nama pemainnya diadaptasi dari nama paman Nabi Abu Jahal disebut Abu jar.

Singkatnya cerita film ini sequel kedua setelah Film Munafik pertama. Cerita dimulai dua tahun setelah peristiwa kematian istri dan putranya di film Munafik, Ustadz Adam (Syamsul Yusof) kini melanjutkan hidup dengan tenang sambil mencoba berdamai dengan masa lalunya. Ustadz Adam melanjutkan kariernya sebagai seorang $D a^{\prime} i$ dan menjalankan keinginannya untuk menolong orang-orang yang terkena gangguan syaithan di mana-mana. Ujian pada episode sebelumnya memberikan pengajaran kepadanya untuk selalu rendah hati kepada Allah SWT. Akan tetapi karena ia merasa bersalah atas kematian Maria, ia sering bermimpi buruk bahkan diteror langsung oleh hantu Maria. Ia dihantui oleh ingatan cerita masa lalu tentang kematian Maria. Adam juga kerap didatangi oleh seorang wanita misterius yang banyak bertanya tentang Taubid, Qada dan Qadar sang Pencipta. Pada waktu yang sama di desa yang berbeda ada seorang perempuan bernama Sakinah (Maya Karin) dan putrinya, Aina yang mencoba menolak ajaran sesat Abu Jar

Sakinah terpaksa harus menjaga Ayahnya yang memiliki penyakit aneh dan tidak diketahui di hutan belantara jauh dari pedesaan. Kehidupan Sakinah yang buruk menjadikan hidupnya dan anaknya penuh tekanan. Dia beberapa kali diganggu oleh Jin kiriman Abu Jar. Sakinah yakin apa yang dia alami berasal dari kiriman Abu Jar, seorang dukun yang berpura pura menjadi pemuka agama, pelopor aliran sesat di desa yang sama. Abu Jar mempunyai banyak pengikut dan orang-orang di desanya pun takut kepadanya. Sakinah atau siapa pun yang masih berpegang teguh pada ajaran Islam yang benar dan tidak mengikuti perintahnya adalah lawan Abu Jar. 
Abu Jar memohon bantuan syaithan dan jin untuk membinasakan semua orang yang tidak mengikuti ajarannya. Hal tersebut membuat Sakinah berusaha menemui Ustadz Adam yang berasal dari desa Seberang untuk membantu ayahnya yang sakit dan membenarkan akidah orang-orang yang ada di desanya. Kedatangan Ustadz Adam ke desa tersebut telah diketahui oleh Abu Jar dan menmbuat kemarahan Abu Jar semakin meningkat. Adam bukan hanya geram dengan apa yang terjadi pada Ayah Sakinah tetapi juga dengan ritual keagamaan buatan Abu Jar yang menyimpang. Ia membengkokkan akidah kaum Muslim di desa tersebut. Saat itu Abu Jar dengan tipu muslihatnya memfitnah Ustadz Adam agar dapat dibunuh olehnya. Tidak hanya itu, untuk melaksankan niat baiknya keselamatan keluarga Ustadz Adam pun terancam.

Pada model Analisis wacana kritis Teun A Van Djik penelitian Film Munafik 2 ini difokuskan pada tiga analisis; yakni teks, kognisi sosial, dan konteks sosial. Hal tersebut selaras dengan tujuan dan fokus penelitian ini. Adapun pembahasannya adalah sebagai berikut:

\section{Analisis Teks}

Pada Analisis Teks penelitian difokuskan pada susunan teks dan wacana yang digunakan untuk menjelaskan suatu tema tertentu. sedangkan pembahasan analisis teks menggunakan tiga tahapan, yakni: Struktur makro, Suprastruktur, dan Struktur mikro.

Pada struktur Makro, ide pokok yang diangkat dalam film ini sesuai dengan judulnya 'Munafik 2' dasar cerita film berdasarkan lika liku perjalanan dakwah seorang da'i menghadapi orang-orang munafik (berpura-pura mengikuti ajaran Islam tapi sebenarnya memungkirinya) dan berbagai macam cobaan yang datang silih berganti. Secara umum Film ini mengandung informasi Islam dan ajakan pada penonton untuk mengidentifikasi Keimanan yang terpatri dalam diri.

Dalam Suprastruktur penelitian difokuskan pada unsur semantik atau korelasi antara struktur wacana dengan kerangka teks. Hal utama yang diamati adalah bagian dan urutan film yang dikemas dalam teks/naskah film yang utuh.

Film ini terdiri dari 47 scene. yakni sebagai berikut:

Scene 1: Ustadz Adam mengejar hantu (Maria) yang ada dalam bangunan tua.

Scene 2: Ayah Ustadz Adam memberi wejangan tentang dakwah.

Scene 3: Sakinah menangisi Ayahnya yang sakit dan ia menyuapi Aina.

Scene 4: Ustadz Adam ceramah di Masjid.

Scene 5: Abu Jar dan pengikutnya akan membakar hidup-hidup Rahman.

Scene 6: Rahim bertemu Azhar di tepi sungai.

Scene 7: Sakinah bertemu Abu Jar di persimpangan jalan hutan. 
Scene 8: Adam bermimpi bertemu Maria di bangunan tua untuk kedua kalinya.

Scene 9: Ustadz Adam bercerita kepada Azman tentang mimpinya.

Scene 10: Abu Jar melakukan ritual keagamaan yang sesat bersama pengikutnya.

Scene 11: Ayah Sakinah kerasukan Syaithan kemudian muncul Syaithan menyerupai Aina.

Scene 12: Sakinah minta tolong ke Azhar untuk melawan sihir Abu Jar Scene 13: Iblis datang temui Ustadz Adam di rumahnya dan bertanya tentang berbagai hal kepadanya.

Scene 14: Azhar datang ke rumah Ustadz Adam untuk memint abnatuan melawan sihir Abu Jar.

Scene 15: Aina diculik Abu Jar.

Scene 16: Ustadz Adam izin pada ibunya untuk pergi ke kampung

Sakinah.

Scene 17: Ustadz Adam pergi ke rumah Sakinah bersama Azman dan Azhar melewati sungai.

Scene 18: Ustadz Adam, Azhar, dan Azman datang ke rumah Sakinah Scene 19: Sakinah kesurupan lalu berlari ke hutan dan menaiki pohon disusul oleh Adam, Azman, dan Azhar.

Scene 20: Abu Jar merendam tengkorak ke dalam air kemudian meminum air yang masuk ke dalam tengkorak tersebut.

Scene 21: Ustadz Adam ta'zৃiah ke Ayah Sakinah

Scene 22: Ustadz Adam didatangi Abu Jar di tepi sungai

Scene 23: Sakinah diganggu Syaithan saat dzikir

Scene 24: Ustadz Adam diganggu Iblis saat perjalanan pulang di sungai.

Scene 25: Ustadz Adam sakit dan mengigau di rumahnya.

Scene 26: Abu Jar akan membunuh Aina di depan pengikutnya.

Scene 27: Sakinah dan Aina bersembunyi di gua.

Scene 28: Ustadz Adam dirasuki Syaithan dan hilang dari rumahnya

Scene 29: Sakinah meninggalkan gua kemudian mencari Aina palsu ke Hutan

Scene 30: Adam kembali bermimpi Maria untuk ketiga kalinya

Scene 31: Adam terbangun di sungai kemudian berdialog dengan Iblis

Scene 32: Sakinah dan Aina dikejar Abu Jar dan pengikutnya.

Scene 33: Sakinah dipukuli Abu Jar dan pengikutnya di hutan.

Scene 34: Ustadz Adam kembali ke rumah dan sedih ibunya mati.

Scene 35: Sakinah diperkosa Abu Jar dan pengikutnya sedangkan

Sakinah disekap di penjara.

Scene 36: Ustadz Adam mendakwahi orang-orang yang disesatkan Abu Jar. 
Scene 37: Pengikut Abu Jar melaporkan kegiatan dakwah Ustadz Adam ke Abu Jar

Scene 38: Abu Jar mendatangi Ustadz Adam yang sedang mendakwahi Warga desa yang mengikuti ajaran sesat Abu Jar.

Scene 39: Azhar mengantar Ustadz Adam pulang

Scene 40: Abu Jar menyusul Ustadz Adam kemudian memukulnya hingga pingsan

Scene 41: Rahim cemaskan Ustadz Adam di rumahnya.

Scene 42: Ustadz Adam disekap dalam peti mati dan ia menemukanmayat-mayat yang disimpan di bangunan tua.

Scene 43: Umar menyarankan Abu Jar untuk membunuh Ustadz Adam

Scene 44: Rahim dan Azhar masuk ke bangunan tua dan menemukan Ustadz Adam kesurupan.

Scene 45: Ustadz Adam difitnah Abu Jar, Sakinah, dan Azman.

Scene 46: Ustadz Adam diseret Abu Jar dan pengikutnya dengan tali tambang.

Scene 47: Ustadz Adam digantung di atas bangunan tua.

Tabel 1. Pengamatan Suprastruktur film Munafik 2

\begin{tabular}{|l|l|}
\hline HAL YANG DIAMATI & PENGAMATAN \\
\hline Adegan Pembuka & $\begin{array}{l}\text { Ustadz Adam Berlari kesana kemari membawa lampu } \\
\text { petromak mencari hantu 'Maria'di bangunan tua. Tiba-tiba } \\
\text { lampu petromaknya berubah menjadi kepala buntung. } \\
\text { Kemudian Ustadz Adam kaget membaca Tau'dz } \\
\text { A'udzubillahiminassaytoonirrajiim(2x }\end{array}$ \\
\hline Alur Cerita & $\begin{array}{l}\text { Ustadz Adam seorang pendakwah diminta bantuan untuk } \\
\text { mengobati Ayah Sakinah yang sakit karena disihir. Ustadz } \\
\text { Adam juga berupaya untuk meluruskan akidah warga } \\
\text { kampung yang ikut aliran sesat Abu Jar. Disisi lain Abu Jar } \\
\text { sangat membenci Ustadz Adam dan ingin mencelakakannya. }\end{array}$ \\
\hline Penyelesaian Masalah & $\begin{array}{l}\text { Ustadz Adam mendatangi kampung tersebut meruqyah Ayah } \\
\text { Sakinah dan mulai berdakwah di desa tersebut. Naasnya } \\
\text { Ustadz Adam difitnah dan dianiaya oleh Abu Jar. }\end{array}$ \\
\hline Adegan Penutup & $\begin{array}{l}\text { Ustadz Adam dalam keadaan berdarah dan luka di seluruh } \\
\text { tubunya digantung di atas bangunan tua oleh Abu Jar. } \\
\text { Kemudian Ustadz Adam memohon ampunan dan } \\
\text { perlindungan pada Allah agar diselamatkan. Tak lama } \\
\text { kemudian terjadilah gempa yang menewaskan Abu Jar dan } \\
\text { pengikutnya. }\end{array}$ \\
\hline
\end{tabular}


Pada Tabel 1 dijelaskan kronologi cerita dimulai dengan adegan Ustadz Adam berlari kesana kemari membawa lampu petromak mencari hantu 'Maria'di bangunan tua. Tiba-tiba lampu petromaknya berubah menjadi kepala buntung. Kemudian ia kaget dan membaca Tau'dz "A'udzubillahiminassaytoonirrajiim".

Alur Film ini bercerita tentang Ustadz Adam seorang pendakwah diminta bantuan untuk mengobati Ayah Sakinah yang sakit karena disihir. Ustadz Adam juga berupaya untuk meluruskan akidah warga kampung yang ikut aliran sesat Abu Jar. Disisi lain Abu Jar sangat membenci Ustadz Adam dan ingin mencelakakannya.

Penyelesaian Masalah dalam film ini dimulai saat Ustadz Adam mendatangi kampung tersebut meruqyah Ayah Sakinah dan mulai berdakwah di desa tersebut. Naasnya Ustadz Adam difitnah dan dianiaya oleh Abu Jar .

Adegan film ditutup dengan kemenangan Ustadz Adam. Saat itu Ustadz Adam dalam keadaan berdarah dan luka di seluruh tubunya digantung di atas bangunan tua oleh Abu Jar. Kemudian Ustadz Adam memohon ampunan dan perlindungan pada Allah agar diselamatkan. Tak lama kemudian terjadilah gempa yang menewaskan Abu Jar dan pengikutnya.

Pada struktur mikro penelitian difokuskan pada analisis semantik, susunan kalimat, stilistik, dan retoris. Keempat elemen yang diamati tersebut meliputi latar, maksud, pola kalimat, koherensi, kata ganti, kosakata, Grafis, dan penggunaan kata yang ada dalam film Munafik 2.

Ditinjau dari sisi semantik, ungkapan kata yang ada pada dialog film menunjukan tiga informasi Islam yang ingin ditekankan. Yaitu; informasi akidah, informasi syariat, dan informasi akhlak Islam.

Ditinjau dari sudut Sintaksis bentuk kalimat yang dipilih dalam film Munafik 2 menggunakan unsur-unsur kalimat sempurna sesuai dengan kaidahnya. Terdiri Subject, Predikat, Object, dan keterangan $(\mathrm{S}+\mathrm{P}+\mathrm{O}+\mathrm{K})$. Misalnya pada Scene 46: Abu Jar berkata kepada Ustadz Adam "aku tidak ingin mendengar kamu ceramah disini"

Aku tidak ingin mendengar kamu ceramah disini

$$
\mathrm{S} \quad \mathrm{P} \quad \mathrm{O} \quad \mathrm{K}
$$

Adapun Stilistik Film Munafik 2 pengamatan difokuskan pada pilihan kata yang digunakan dalam dialog film. Karena film ini berasal dari Malaysia maka dialog dalam Film Munafik 2 menggunakan bahasa Melayu Malaysia.

Secara retoris pengamatan difokuskan pada elemen metafora. pengamatan ditunjukan pada gaya bahasa (majas) yang digunakan oleh pemain film Munafik 2. Ada beberapa majas yang digunakan dalam film Munafik 2 diantaranya majas perbandingan, sindiran, penegasan, dan Pertentangan. 
Tabel 2. Majas yang digunakan dalam film Munafik 2

\begin{tabular}{|c|c|}
\hline Jenis Majas & Contoh kalimat \\
\hline Majas Metafora & Inilah Fir'aun di zaman ini! \\
\hline Majas Hiperbola & $\begin{array}{l}\text { Cari petunjuk di dalam jiwamu! Agama Hidup dalam darah } \\
\text { daging Adam }\end{array}$ \\
\hline Depersonifikasi & $\begin{array}{l}\text { Allah samakan Ulama yang mengharapkan kemewahan dunia } \\
\text { seperti Anjing. }\end{array}$ \\
\hline Sarkasme & Menjadi istri atau budak pemuas hawa nafsu Syaithanmu? \\
\hline Satire & $\begin{array}{l}\text { Tuhan dekat dengan kamu? Kita juga dekat. Jadi apa bedanya? } \\
\text { Bagaimana kamu bisa bilang dekat dengan Tuhan? Apa kamu } \\
\text { bisa melihat Tuhanmu? } \\
\text { Oh ini rupanya Ustadz Adam! Biasa aja orangnya. Tidak } \\
\text { memakai sorban. Tetapi malah mengaku mengikuti Sunah } \\
\text { Rasulullah. Sepengetahuan aku yang namanya Ustadz itu akan } \\
\text { mati matian mengikuti perintah Nabi-Nya. Ahli Sunnah wal } \\
\text { Jamaah apa kamu ini? }\end{array}$ \\
\hline Sinisme & $\begin{array}{l}\text { Kebenaran apa? kamu hanya membawa kesesatan. Ilmu yang } \\
\text { kamu dapatkan itu dari Syaithan, bukan dari Tuhan. }\end{array}$ \\
\hline Repetisi & $\begin{array}{l}\text { Allah samakan ulama yang mengharapkan kemewahan dunia } \\
\text { seperti Anjing. Perumpamaan ulama seperti ini, sama seperti } \\
\text { Anjing. Naudzubillah } \\
\text { Aku tidak akan pernah sudi ikut ajaran kamu! Tidak akan } \\
\text { pernah! } \\
\text { Aku akan pastikan kamu akan menyesal seumur hidup kamu } \\
\text { Adam! SEUMUR HIDUPMU! }\end{array}$ \\
\hline Klimaks & $\begin{array}{l}\text { Talbis Iblis, Iblis jika ingin menyesatkan manusia, ia akan } \\
\text { melakukan Talbis. Talbis itu Izharul Bathil Fïsuuratil Haq. } \\
\text { Membenarkan pekerjaan yang salah. Perkara yang Bathil, dikira } \\
\text { pekerjaan yang benar. }\end{array}$ \\
\hline Retoris & $\begin{array}{l}\text { Siapa kamu berani berbicara tentang dalil agama? kamu } \\
\text { seharusnya hormati aku. Malah tiba-tiba muncul di desa ku. } \\
\text { Sudah berapa banyak Hadist yang kamu hafal? Seribu? Dua } \\
\text { Ribu? } \\
\text { Sayidina Umar sahabatnya Nabi pun sendiri pernah } \\
\text { mengatakan jika kalian lihat aku menyeleweng, maka tegurlah } \\
\text { aku. Itu kata sayidina Umar. Apalagi ini hanya Abu Jar yang } \\
\text { sudah jelas ke Kufurannya. kita bukan jahiliyah. }\end{array}$ \\
\hline
\end{tabular}


Megandini A Fiqri, Sitty Sumijati, Asep Shodiqin

\begin{tabular}{|l|l|}
\hline Eksklamasio & Allahu Akbar! Aku Tidak akan mengikuti ajaranmu! \\
\hline
\end{tabular}

Pada Tabel 2 di atas dijelaskan beberapa Majas yang digunakan dalam Film Munafik 2. Misalnya pada kalimat "Inilah Fir'aun Zaman ini" pada kata Fir'aun menunjukan bahwa orang yang bersangkutan sifatnya kejam, sombong, dan jahat. tentu perumpamaan yang digunakan masuk ke jenis Majas Metafora yakni berupa kiasan untuk menggambarkan sesuatu.

Komponen yang diamati dalam analisis teks meliputi unsur topik, bentuk kalimat, leksikon, grafis metafora, skema, latar, detail, dan maksud. Analisis tersebut disusun dalam struktur makro, mikro, dan suprastruktur. (Sobur, 2001: 67)

\section{Kognisi Sosial}

Pada Kognisi Sosial pengamatan difokuskan pada analisis penulis terhadap informasi Islam yang ada dalam Film Munafik 2. Proses kognisi sosial diawali dengan pengamatan ungkapan kata pada dialog film yang menunjukan tiga informasi Islam yang ingin ditekankan. Yaitu; informasi akidah, informasi syariat, dan informasi akhlak Islam.

Informasi Akidah Islam adalah keseluruhan makna pesan yang disampaikan oleh pemeran adegan dalam film Munafik 2 hal ihwal tentang kepercayaan dasar pada Tuhan atau keterangan pesan yang mengacu pada akidah Islam. Misalnya pada scene 4 dan 5 dalam Film Munafik 2.

Tabel 3. Scene 4 Ustadz Adam berceramah di Masjid

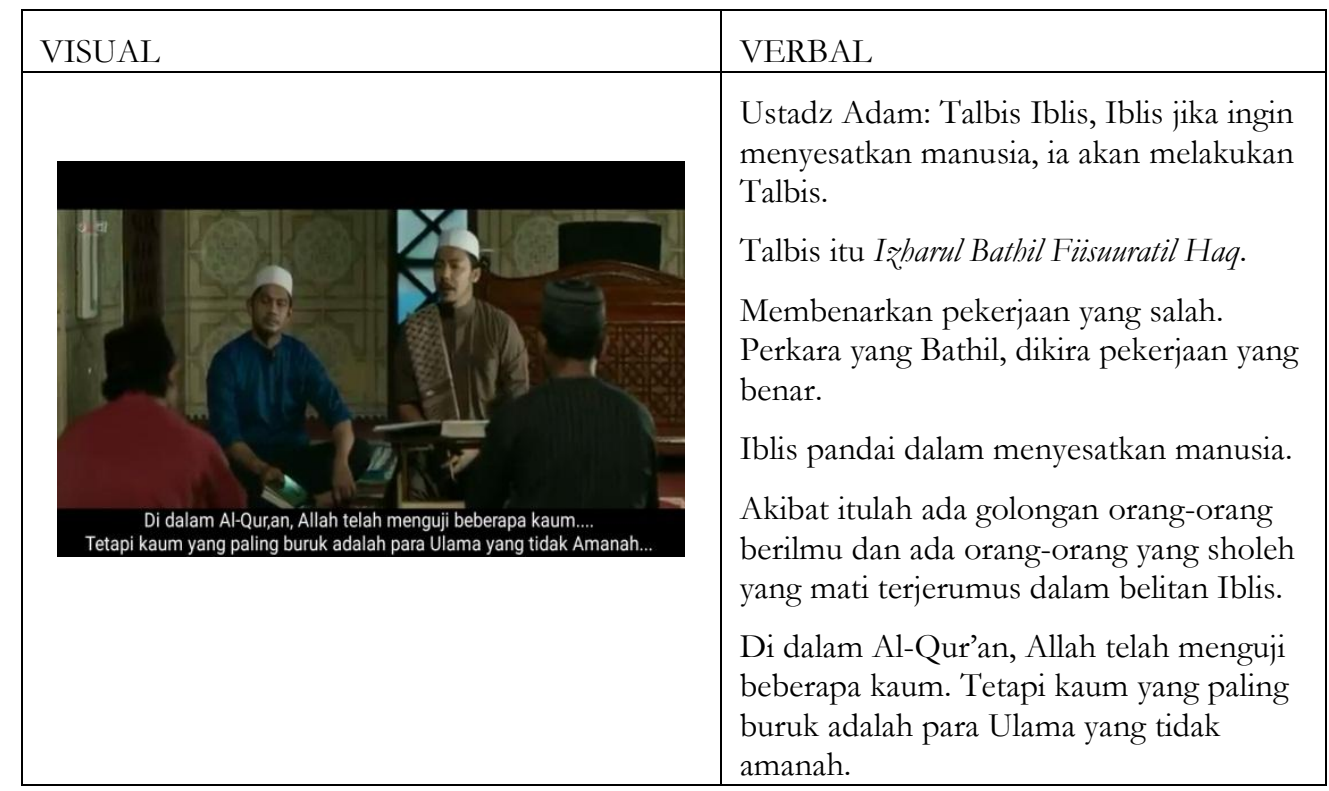




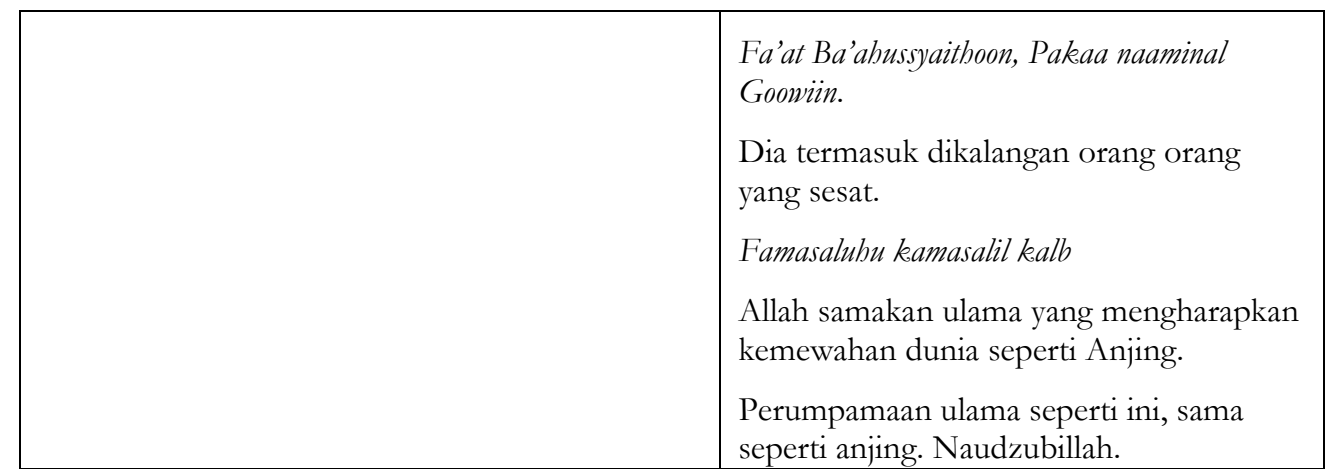

Gambar Sumber: Screenshoot Film Munafik 2

Tabel 4. Scene 5 Abu Jar dan pengikutnya akan membakar hidup-hidup Rahman

\begin{tabular}{|l|l|}
\hline \multicolumn{1}{|c|}{ VISUAL } & \multicolumn{1}{c|}{ VERBAL } \\
\hline Rahman: (Abu Jar dan pengikutnya \\
mendatangi Rahman yang berlumuran darah \\
dan tangannya diikat kebelakang dengan Tali \\
tambang) Tobatlah Abu Jar! Takutlah kamu \\
kepada Allah! \\
Sampai kapan kamu terus membunuh semua \\
orang yang mau menegakan agama Allah. \\
Abu Jar: Kamu percaya kepada Allah dan \\
Rasul. Tapi kenapa kamu tidak mau percaya \\
kepada aku dan ajaran ku. \\
Aku juga berjihad di jalan Allah \\
Rahman: Kamu ingkar kepada Al Qur'an! \\
Kamu ingkar juga kepada Hadist! \\
Pengikut Abu Jar: Apa yang kamu ketahui \\
Rahman? Kamu ingin menuduh Abu Jar \\
Munafik? Tapi kamu itu yang Munafik! \\
Janganlah kamu melawan Abu Jar, Terima \\
saja ajaran kami Rahman. Atau kamu akan \\
berakhir seperti mayat-mayat itu! \\
Kamu takut kan Rahman? \\
Rahman: Aku hanya takut kepada Allah. \\
kalian semua sudah sesat! \\
Abu Jar: Tidak ada satupun yang bisa \\
menghalangi orang lain untuk jadi pengikut \\
aku.
\end{tabular}

Tabligh: Jurnal Komunikasi dan Penyiaran Islam Vol. 5 No. 1 (2020) 57-76 


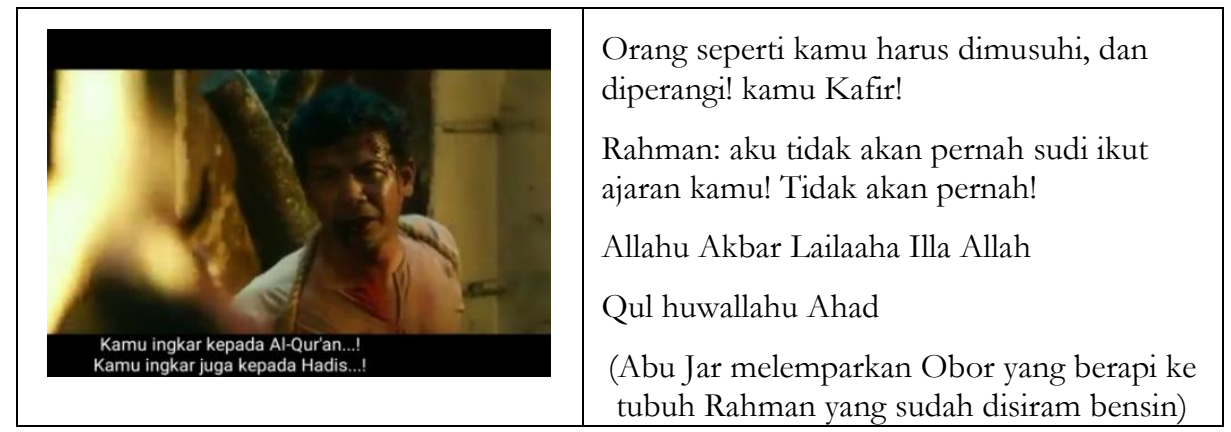

Sumber: Screenshoot Film Munafik 2

Berdasarkan hasil analisis informasi Akidah Islam tertuang dalam beberapa scene dalam film Munafik 2 yang mengandung informasi berupa ajakan untuk Selalu Diøkrullah (mengingat Allah) pada kondisi apapun, dimanapun dan kapanpun. Selalu memohon perlindungan pada Allah SWT dari segala marabahaya. Senantiasa berhati hati dan sebisa mungkin menjauhi Talbis. Taubidullah, menjadikan Allah SWT satu-satunya Dzat yang disembah. Mengesakan Allah dalam segala aspek Rububiyah, Ulubiyah, dan Asma wa Siffat. Serta tidak menyekutukan-Nya dengan apapun. Takut hanya kepada Allah SWT. Berpegang teguh pada ajaran Allah. Tidak menukar Iman dengan hal apapun. Membangun kesadaran bahwa hidayah itu milik Allah dan Allah dekat dengan hambanya. Serta adanya informasi tentang kemunculan tokoh eskatologi Islam.

Sedangkan hasil analisis lainnya menunjukan Informasi syariat dalam scene tertentu dalam film Munafik 2. Informasi Syariat Islam adalah keseluruhan makna pesan yang disampaikan oleh pemeran adegan dalam film Munafik 2 hal ihwal yang berkaitan dengan hukum agama, hubungan manusia dengan Tuhan, atau keterangan pesan yang mengacu pada aturan Islam. Misalnya pada Scene 2 dan scene 39 dalam Film Munafik 2.

Tabel 5. Scene 2: Ayah Ustadz Adam memberi wejangan tentang dakwah

\begin{tabular}{|l|l|}
\hline VISUAL & VERBAL \\
\hline Mudah-mudahan Adam bisa lstiqomah... & $\begin{array}{l}\text { Rahim: (Berbicara kepada istrinya) Syarat } \\
\text { seseorang untuk menjadi pemimpin yang } \\
\text { membimbing manusia ke jalan Allah adalah } \\
\text { SABAR. } \\
\text { Hendaklah dia bersabar demi meneruskan } \\
\text { perjuangan dan tanggung jawab untuk } \\
\text { membela Islam. } \\
\text { Menyampaikan pesan dengan } \\
\text { KEBENARAN. Dan menyampaikan pesan } \\
\text { dengam KESABARAN. } \\
\text { Tidaklah mudah untuk menjadi seorang }\end{array}$ \\
\hline
\end{tabular}




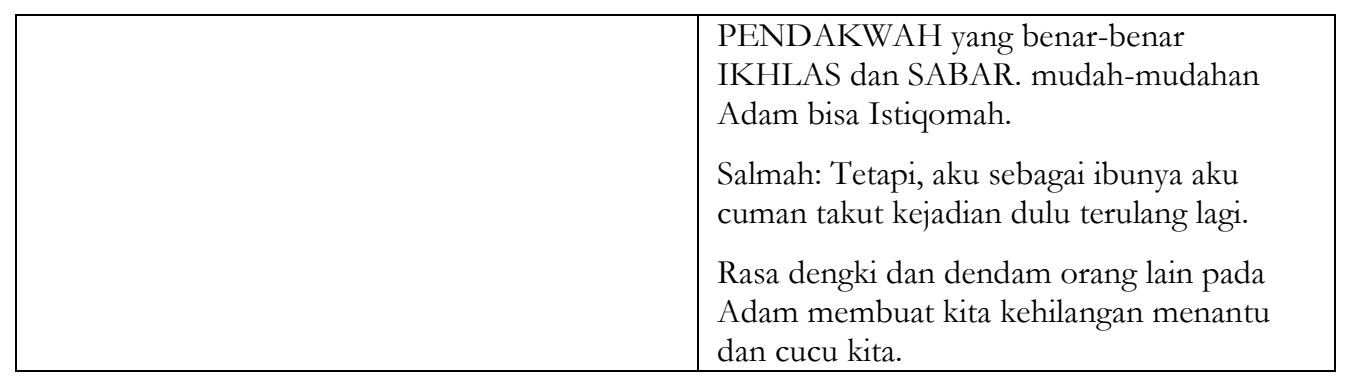

Sumber: Screenshoot Film Munafik 2

Tabel 6. Scene 39: Azhar mengantar Ustadz Adam pulang dicegat Abu Jar

\begin{tabular}{|c|c|}
\hline VISUAL & VERBAL \\
\hline & $\begin{array}{l}\text { Azhar: Selama ini aku sudah berdosa Adam. } \\
\text { Padahal aku tahu kalau ajaran Abu Jar ini sesat. } \\
\text { Tapi aku tak berani aku takut untuk membela } \\
\text { agama aku sendiri. Aku bukan bermaksud } \\
\text { mementingkan diriku sendiri Adam. Tapi? } \\
\text { Ustadz Adam: Cukuplah kamu lawan ajaran } \\
\text { Abu Jar itu dengan hati saja Azhar. Sebab aku } \\
\text { tahu kamu tidak mampu. Tidak apa-apa Azhar. } \\
\text { Insyaallah keikhlasan kita yang akan dinilai Allah } \\
\text { di akhirat nanti. } \\
\text { Azhar: Tetapi melawan kemunkaran hanya } \\
\text { dengan hati Adam adalah selemah lemahnya } \\
\text { Iman Adam. } \\
\text { Ustadz Adam: Memang melawan kemunkaran } \\
\text { itu hukumnya wajib bagi setiap umat muslim. } \\
\text { Tetapi juga dilihat dari kemampuan dan } \\
\text { kekuatan engkau. Bersabarlah Azhar. } \\
\text { Azhar: Dulu aku punya istri Adam. Tapi istri } \\
\text { aku durhaka kepadaku sebab pengaruh dari } \\
\text { ajaran Abu Jar Adam. Disebabkan ia sudah } \\
\text { terlalu tergoda. Dia tinggalakan aku sendirian. } \\
\text { Hidayah itu memang milik Allah dan Tidak } \\
\text { semua orang bisa mendapatkannya. Karena } \\
\text { itulah sampai hari ini. Aku terus berdoa Adam } \\
\text { sehari-hari. Supaya istri aku mau kembali } \\
\text { memeluk agama Islam. } \\
\text { Ustadz Adam: Dalam memperjuangkan agama } \\
\text { Islam ini tidak semuanya indah Azhar. Tidak } \\
\text { semuanya indah. }\end{array}$ \\
\hline
\end{tabular}

Gambar Sumber: Screenshoot Film Munafik 2 
Megandini A Fiqri, Sitty Sumijati, Asep Shodiqin

Analisis dari tabel pada scene-scene tersebut menunjukan bahwa menyampaikan pesan kewajiban dakwah itu wajib terutama jika disampaikan dengan kebenaran dan kesabaran. Menegakkan Amar ma'ruf dan nabyi munkar. Qur'an dan Sunnah sebagai Pedoman hidup, Sumber hukum, dan ajaran Islam. serta informasi seputar tingkatan kemampuan dakwah dan kualitas hadits.

Adapun informasi Akhlak Islam dalam film Munafik 2 mengacu pada etika sehari hari. Yaitu makna pesan yang disampaikan oleh pemeran adegan dalam film Munafik 2 hal ihwal yang berkaitan dengan budi pekerti, etika, moral baik-buruk ditinjau dari sisi Islam atau keterangan pesan yang mengacu pada akhlak Islam. Misalnya pada scene 16 Film Munafik 2.

Tabel 7. Scene 16: Adam izin pada ibunya untuk pergi ke kampung Sakinah

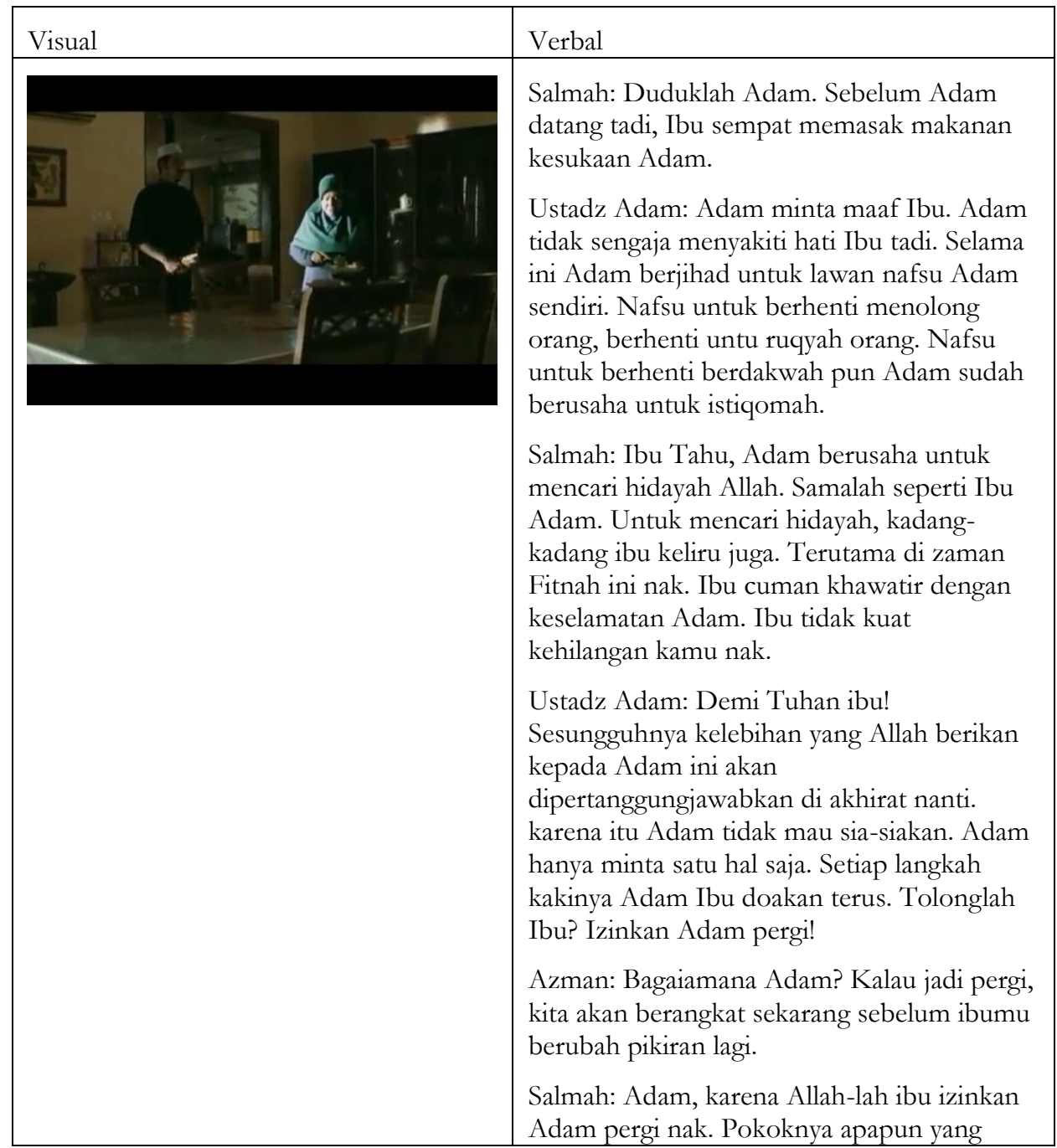




\begin{tabular}{|l|l|}
\hline & $\begin{array}{l}\text { terjadi. Ibu harapkan kamu harus kembali } \\
\text { malam ini juga. } \\
\text { Ustadz Adam: Insyaallah Ibu. }\end{array}$ \\
\hline
\end{tabular}

Gambar Sumber: Screenshoot Film Munafik 2

Berdasarkan hasil analisis pada scene 16 mengandung informasi agar Ikhlas dalam beribadah (salah satunya berdakwah). Berbakti dan menghormati Orang tua terutama Ibu. Dan sabar menghadapi cobaan dari Allah SWT. Dan apa yang tertuang dalam scene tersebut merupakan contoh informasi Akhlak Islam.

Asas kognisi sosial sama dengan asas belajar observasional. Dimulai dengan meneliti tingkah laku seseorang yang dihasilkan dari proses conditioning (Pembiasaan merespon) dan proses imitation (Peniruan) dari figur sebagai contoh bersosialisasi dan moral (Sudjatnika, 2016: 159)

\section{Konteks Sosial}

Konteks sosial pada analisis wacana kritis Teun A Van Djik memiliki arti yang sama dengan kritik sosial. analogi konteks sosial film Munafik 2 sama halnya dengan penilaian serius hasil karya sineas terhadap film yang diproduksi. komponen yang dinilai berupa baik-buruk sebuah tayangan, kelebihan dan kekurangan Film yang memiliki landasan logis.

Ditinjau dari segi konteks Sosial Film Munafik 2 ini cukup baik. Film ini bergenre horror religi akan tetapi secara umum Film ini disajikan secara ciamik sehingga memantik penonton untuk intropeksi diri. Meskipun demikian ada beberapa hal yang perlu diulas kembali dan menjadi kritik sosial yakni;

Dalam Film tersebut sebagai tokoh Utama protagonist Ustadz Adam diceritakan sebagai tokoh agama yang beriman, pemberani, rajin ibadah, berdakwah, dan sering membantu merukyah orang yang kerasukan. Pada akhir film diceritakan bahwa Adam dirasuki oleh syaithan dan membunuh ibunya sendiri. Hal tersebut tentu berlawanan dengan realitas umum bahwa seorang yang baik, berilmu dan taat beragama pasti selalu dalam lindungan Allah SWT dan jauh dari godaan syaithan yang terkutuk. Akan tetapi pada kenyataannya Ustadz Adam dirasuki sampai membunuh Ibunya sendiri.

Apa yang terjadi pada Ustadz Adam dalam film tersebut sebenarnya mengandung makna pesan tersirat bahwa Orang sehebat Ustadz Adam pun tak lepas dari godaan syaithan yang terkutuk. Realitas tersebut juga menggiring opini yang melekat di masyarakat bahwa banyaknya ibadah seseorang belum bisa menjamin keselamatannya dari segala marabahaya. Pondasi ibadah yang harus dilandasi dengan keikhlasan pun tidak dapat terlihat dari luar melainkan hanya Allah yang Maha Mengetahui. Tidak ada manusia yang luput dari dosa dan kesalahan. 
Akan tetapi Plot Twist yang disajikan dalam film Munafik 2 secara tidak langsung bahkan menjadi plot hole bagi penonton. Meski inti pesan yang ingin disampaikan kepada penonton bahwa keimanan seseorang (Adam) itu fluktuatif. Tetapi tetap saja alur ceritanya terkesan dipaksakan, tak logis, dan tidak sesuai dengan alur cerita yang sudah dibangun sebelumnya.

Selain itu pesan-pesan yang ada dalam film Munafik 2 secara umum merujuk pada informasi Islam. Inti pesannya bagus bisa menjadi self-reminder bahan renungan bagi siapa saja yang menontonnya. Hanya saja pesan pesan yang disampaikan cenderung terlalu ekspilisit. Misalnya ada beberapa adegan dialog dalam film ini yang menampilkan Ustadz Adam membaca do'a saat mengobati orang yang kerasukan menggunakan bahasa Arab atau ceramah beliau di depan mad'u nya yang secara langsung dan gamblang. Sekilas pesan yang disampaikan jelas, akan tetapi hal tersebut mengurangi efektivitas dakwah dalam media film yang notabenenya pesan-pesannya disampaikan kepada penonton secara halus dan menyentuh relung hati tanpa merasa digurui. sebaliknya pada bebrapa scene tersebut cara berdakwahnya tidak dikemas dengan halus dan kurang sesuai dengan mediumnya.

Karya pustaka yang mengandung kritik adalah sasaran yang menarik untuk dianalisis. Karya tersebut digunakan agar mendapatkan perubahan di beberapa elemen tertentu. Baik di tataran politik, sosial, maupun budaya. Setiap produksi film yang diciptakan, selalu mengandung nasihat dan kritik terhadap masyarakat. (Prakoso, 2012: 3)

\section{PENUTUP}

Berdasarkan hasil Analisis wacana kritis pada Film Munafik 2, dapat disimpulkan sebagai berikut:

Analisis teks dalam film Munafik 2 diuraiakan melalui tiga tingkatan yakni: struktur makro, suprastruktur dan struktur mikro. Pada struktur makro tema yang diangkat film Munafik 2 yakni tentang kemunafikan. Secara suprastruktur film ini terdiri dari 47 scene menggunakan alur cerita campuran. Sedangkan pada struktur Mikro, secara semantik film ini mengarahkan pada dakwah Islam menggunakan bahasa melayu dengan majas retoris, repetisi, dan satire.

Pada kognisi sosial menunjukan banyak informasi Islam dalam Film Munafik 2 yang dapat dijadikan Uswah hasanah (Contoh yang baik) bagi penonton. Film Munafik 2 bukan hanya sekadar dijadikan tontonan melainkan tuntunan. Ada 3 Informasi penting yang dapat diambil dalam film Munafik 2 yakni informasi Akidah, informasi Syariat dan informasi Akhlak.

Film Munafik 2 secara umum disuguhkan cukup baik, sehingga memantik penonton untuk intropeksi diri. tetapi ditinjau dari konteks sosial menggunakan alur cerita film plot twist ini cenderung menjadi plot hole karena alur yang berubah pada akhir cerita. Sehingga memuat paradoks bagi penonton. Yakni dengan adanya alur cerita film yang berlawanan dengan realitas yang ada di masyarakat. 
kemudian beberapa pesan yang disampaikan terkesan terlalu eksplisit sehingga tidak sesuai dengan medium film sebagai media dakwah yang disampaikan secara halus dan menyentuh relung hati penonton.

Saran dalam penelitian ini yakni ditujukan khususnya untuk para Sineas muda yang memiliki passion dalam membuat film khususnya Sineas Muslim hendaklah memberikan ruang untuk membuat film yang memilki manfaat bagi umat Islam dan bisa dijadikan sebagai media dakwah Islam. Film yang dapat dijadikan sarana amar ma'ruf dan nahyi munkar. Film yang menyentuh relung hati penonton dengan cerita segar dan inspiratif. Tingkatkan kreativitas kalian dalam membuat Film Dakwah yang tidak hanya sekadar menjadi tontonan tapi tuntunan.

Sedangkan saran untuk penonton atau penikmat Film. Jadikanlah Film yang bermuatan dakwah sebagai tontonan pilihan. Beri dukungan dan apresiasi pada Sineas muda yang memiliki karya film bermuatan dakwah dengan menontonnya di bioskop atau youtube. Serap dan amalkan informasi dan edukasi baik yang ada dalam film. Amati film yang ditonton dan ambil hikmah yang ada dalam film tersebut.

Adapun saran Untuk Peneliti selanjutnya, penelitian seperti ini perlu dibuat lebih baik lagi. Dari segi Latar belakang penelitian, Teori, hingga hasil penelitian perlu dikembangkan lebih mendalam agar penelitian ini dapat menjadi contoh yang baik penelitian lainnya.

\section{DAFTAR PUSTAKA}

Aziz, M. A. (2004) Ilmu Dakwah. Jakarta: Prenada Media

Baskin, A. (2003) Membuat Film Indie Itu Gampang. Bandung: KATARSIS

Darma, Y A. (2014) Analisis Wacana Kritis. Bandung: Refika Aditama

Effendi, O. U. (2003) Televisi Siaran dan Praktek, Bandung: Mandar Maju

EffendI, O. U.(2003). Ilmu, Teori dan Filsafat Komunikasi. Bandung: PT. Citra Aditya Bakti

Enjang AS, Aliyudin. (2009). Dasar-dasar Ilmu Dakwah. Bandung: Widya Padjajaran

Kusnawan, A, dkk. (2004). Komunikasi \&Penyiaran Islam, Bandung: Benang Merah Press

Kusnawan, A, et, al., (2009). Dimensi Ilmu Dakwah. Bandung: Widya Padjajaran Luhukay, M. S. (2008). Analisis Film Artificial Intelligence (AI) Pada Aspek Sosial, Kultural Dan Teknologi. Jurnal Ilmiah SCRIPTURA: Vol. 2, No. 2, Juli 2008: 124 - 134

Muhaemin, E. (2017) Dakwah Digital Akademisi Dakwah dalam Ilmu Dakwah: Academic Journal For Homiletic Studies, 11 (2), 341-356

Nursyamsi, Y.F. (2018) Analisis Wacana Pesan Dakwah pada Film Cinta dalam Ukhuwah dalam Tabligh: Jumal Komunikasi dan Penyiaran Islam, 3 (1), 91-110 
Megandini A Fiqri, Sitty Sumijati, Asep Shodiqin

Putra, H. (2018) Munafik 2, diakses tanggal 24 Oktober 2018 https://id.m.wikipedia.org/wiki/Munafik_2

Saputra, W. (2012) Pengantar Ilmu Dakwah, Jakarta: Rajawali Press

Sobur, A. (2001) Analisis Teks Media. Bandung: Rosda

Soleh, A. (2019). Pola Komunikasi Kelompok pada Komunitas Pecinta Film Islami dalam Anida: Aktualisasi Nuansa Ilmu Dakwah, 19 (1), 16-33

Sudjatnika, T. (2016) Tinjauan Kognisi Sosial terhadap Sosial Budaya dalam Jurnal al-Tsaqafa, 13 (01), 159-176 